\title{
Interannual variability and lagged correlation during strong El Niño events in the Pacific Ocean
}

\author{
You-Soon Chang ${ }^{1, *}$, Dongchull Jeon ${ }^{2}$, Homan Lee ${ }^{1}$, Hui Soo An ${ }^{3}$, Jang-Won Seo', \\ Yong-Hoon Youn ${ }^{1}$ \\ ${ }^{1}$ Marine Meteorology and Earthquake Research Laboratory, Meteorological Research Institute, Seoul 156-720, South Korea \\ ${ }^{2}$ Ocean Environment and Climate Division, Korea Ocean Research and Development Institute, Ansan PO Box 29, \\ Seoul 425-600, South Korea \\ ${ }^{3}$ Department of Earth Science Education, Seoul National University, Seoul 151-742, South Korea
}

\begin{abstract}
Interannual climate variability in the Pacific Ocean is investigated using historical data for precipitation, sea-surface temperature (SST) and sea-surface height (SSH). Emphasis is placed on examining the regional correlation, teleconnection patterns and their time lags. Spatial and temporal relationships are examined using empirical orthogonal functions (EOFs), wavelet transform and cross correlation analyses. All the analyzed data derived from first modes of EOFs show interannual variability very similar to those of Niño indices. Associated time series from second modes of EOFs explaining strong El Niño episodes have a high correlation with those of first modes at a time lag of about 9 to 11 mo. Spatial distributions of the strong El Niño modes and the lagged correlations with Niño3 region show a possible teleconnection pattern of the eastward migration of the Pacific climate system.
\end{abstract}

KEY WORDS: Interannual variability - Regional correlation - Teleconnection - EOF - Wavelet transform $\cdot$ Cross correlation $\cdot$ Strong El Niño

\section{INTRODUCTION}

Interannual variability of the ocean and atmospheric phenomena has been recognized as an indicator of global climate change (Horel \& Wallace 1981, Rasmusson \& Wallace 1983, Glantz et al. 1991). Numerous researchers have studied the interannual variation in sea-surface temperature (SST), as a measure of the ocean heat content, relative to the El Niño phenomenon (Davis 1976, Weare et al. 1976, White et al. 1985a,b, Hanawa et al. 1988). In all these studies, positive anomalies of heat content of the western tropical Pacific have been shown to occur at the beginning of the El Niño events and negative anomalies during the mature phase. Other research focused on the transfer of heat content or related variables between the equatorial and higher latitudes, using either satellite altimetry (Miller \& Cheney 1990, Gael \& Thierry 2002), island-based sea-level stations (Wyrtki 1985), upper-layer temperature measurements (Trenberth et al. 1998, Meinen \&
McPhaden 2001), or rainfall gauges and satellite precipitation measurements (Chang et al. 2002). All these results imply that the El Niño signal extends beyond the equatorial regions with some time lag.

Fig. 1a shows the time series of the SST anomalies of Niño indices (Niño4, Niño3.4, Niño3, Niño1+2, arranged by the spatial sequence from west to east Pacific from 1980-2000). The most noticeable feature is that SST anomalies are much higher during El Niño years than in normal years. Another prominent feature relates to an eastward propagating pattern during strong El Niño episodes, 1982-1983 and 1997-1998, shown by the shaded regions in Fig. 1. This propagating signal can be confirmed in the variation of trade winds at a level of $850 \mathrm{hPa}$ as well (Fig. 1b). Westerly wind anomalies (negative value) during strong El Niño episodes become much stronger than in weaker El Niño years (1986-1987, 1991-1992) and propagate toward the eastern Pacific. This is indicative of the well-known mechanism of equatorial Kelvin waves 
(a) SST index

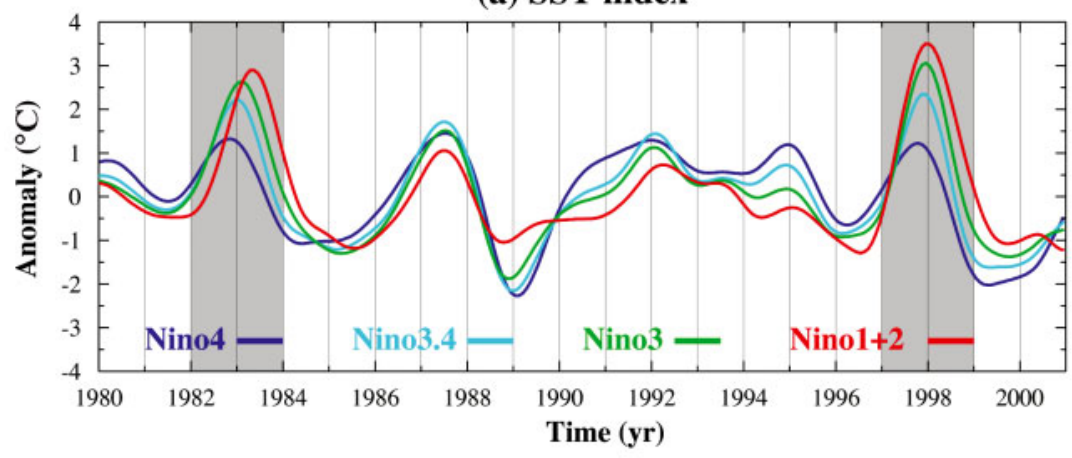

(b) Trade Wind index

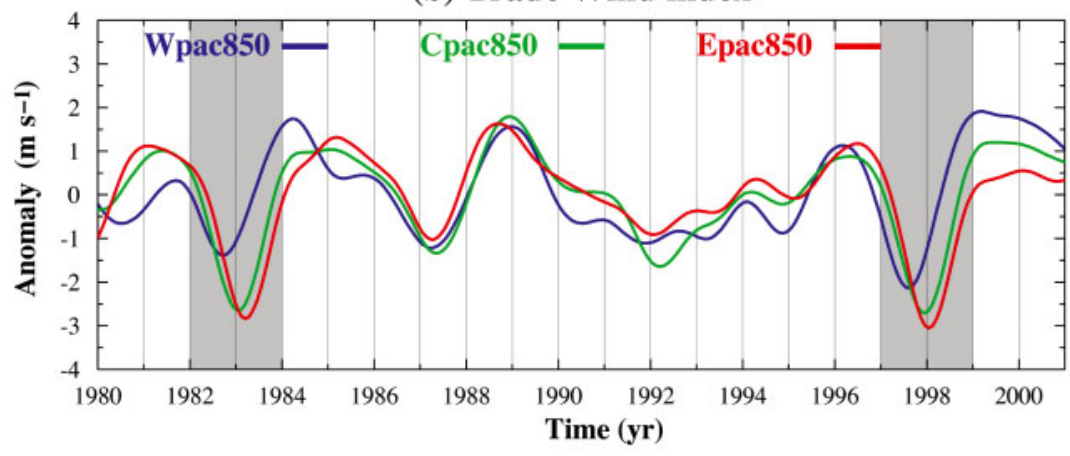
voluted using a 24 mo Hanning filter. Shaded regions indicate strong El Niño episodes. Each index is defined as follows: Niño4 $\left(160^{\circ} \mathrm{E}-150^{\circ} \mathrm{W}\right.$, $\left.5^{\circ} \mathrm{N}-5^{\circ} \mathrm{S}\right)$, Niño3.4 $\left(170-120^{\circ} \mathrm{W}, 5^{\circ} \mathrm{N}-5^{\circ} \mathrm{S}\right)$, Niño3 $\left(150-90^{\circ} \mathrm{W}, 5^{\circ} \mathrm{N}-5^{\circ} \mathrm{S}\right)$, Niño1+2 $\left(90-80^{\circ} \mathrm{W}, 0-10^{\circ} \mathrm{S}\right), \mathrm{Wpac} 850\left(135^{\circ} \mathrm{E}-180^{\circ}, 5^{\circ} \mathrm{N}-5^{\circ} \mathrm{S}\right), \mathrm{Cpac} 850$ $\left(175-140^{\circ} \mathrm{W}, 5^{\circ} \mathrm{N}-5^{\circ} \mathrm{S}\right)$, and Epac850 $\left(135-120^{\circ} \mathrm{W}, 5^{\circ} \mathrm{N}-5^{\circ} \mathrm{S}\right)$
Fig. 1. El Niño indices showing (a) SST and (b) trade wind anomalies con-

Xie \& Arkin (1997), called the Climate Prediction Center (CPC) Merged Analysis of Precipitation (CMAP), for 1979-1999. The variation of SST was investigated from 1979-1999 using the reanalyzed data provided by the National Center for Environmental Prediction (NCEP). Monthly-mean sea-level data obtained from the University of Hawaii Sea Level Center (UHSLC) for $21 \mathrm{yr}$ (1978-1998) were also used. As there is a large amount of missing data during 1999, the period 1978-1998 was used.

Missing data in time series were replaced using the weight-folding algorithm suggested by Jeon (1995), as long as the gap in the data was not longer than 18 mo. The weight-folding algorithm basically assumes that the memory of the previous datum has an influence on a present datum to some degree, and that the correlation between them becomes lower with increasing time difference. Fig. 2 is an example of the weight-folding interpolation method for a case of monthly time series with a gap of $11 \mathrm{mo}$. The dotted line between B0 and A0 is a linear regression, and $\mathrm{C}_{i}^{\prime}$ s are created data from $\mathrm{A}_{i}$ 's and $\mathrm{B}_{i}{ }^{\prime} \mathrm{s}$ with weight. This method reflects the periodic characteristics of raw data and simplifies the interpolation algorithm.

propagating along the Equator (Wyrtki 1975, 1985). Recently, Jin et al. (2003) have explained the eastward-propagating El Niños and their strong intensity using nonlinear heating dynamics. However, their study was limited to near the tropical Pacific.

If there are propagating motions during strong El Niños in the tropical regions, then oceanic and atmospheric conditions of other regions may also be affected but with time lags. In light of this, the emphasis here is on examining the regional correlation of the El Niño signal between the equatorial Pacific and mid-latitudinal regions. In this study, the lagged correlation of interannual variability is investigated from historical precipitation, SST and SSH (seasurface height) data.

\section{METHOD}

Precipitation, SST and $\mathrm{SSH}$ in the Pacific area $\left(110^{\circ} \mathrm{E}-90^{\circ} \mathrm{W}, 10^{\circ} \mathrm{S}-50^{\circ} \mathrm{S}\right)$ were chosen as indicators of the atmospheric and oceanic variation. We used the monthly averaged $2.5^{\circ}$ by $2.5^{\circ}$ gridded data set from
Long-term linear trends and high frequencies were eliminated by detrending the least-squared fits and

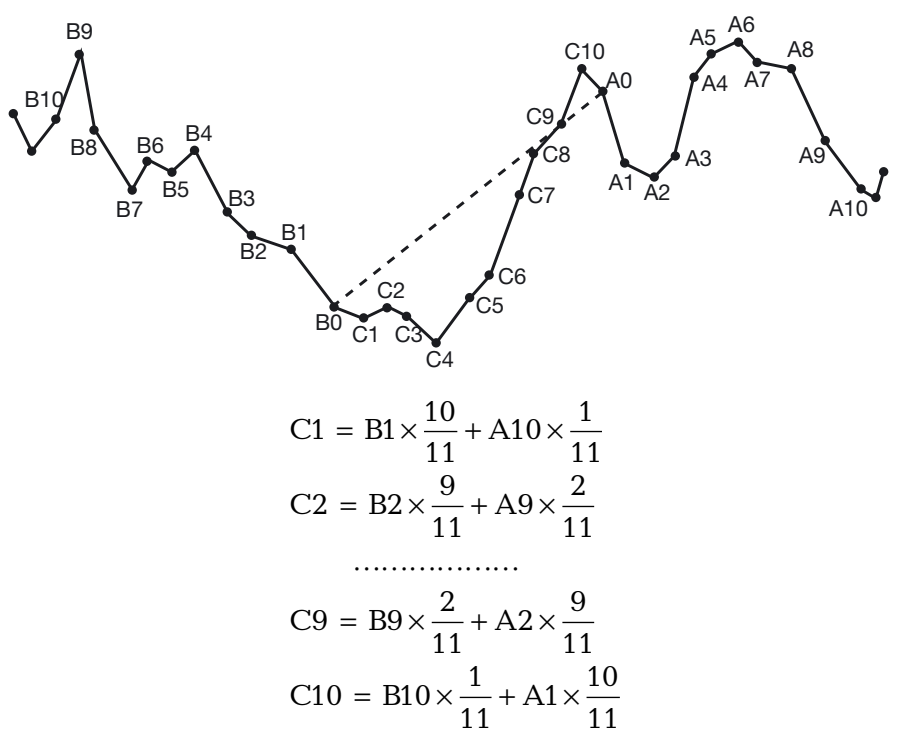

Fig. 2. Weight-folding interpolation algorithm (after Jeon 1995) 
by cutting off at the 24 mo period with a low-pass Hanning filter, respectively. The aim here is to focus on interannual fluctuation in the time series of raw data and to analyze the periodicity. In order to compare the relative spatial variations of each data set, we used normalized data (anomalous data divided by the corresponding standard deviations).

Correlation maps indicate the spatial variability of a climate system but cannot provide any detail about temporal variability. To examine simultaneously their spatial and temporal variability, empirical orthogonal functions (EOFs) and cross-correlation analysis were used. The primary advantages of these methods are their ability to extract the dominant temporal and spatial components from the complicated variability of the original data set and their ability to check for the time-delayed mode contained in veiled signals such as El Niño propagation in the mid-latitudinal regions. To show the periodic characteristics of principal time components, spectral analysis using wavelet transform was also carried out. Unlike the Fourier transform, which describes the overall regularity of signals, wavelet transform can calculate a signal's evolution in time, such as strong El Niño propagation. In this study, the Morlet base wavelet in the form of a Gaussian function was used (Meyer et al. 1993).

\section{TYPICAL AND STRONG EL NIÑO MODES OF EOF ANALYSES}

Chang et al. (2002) performed an EOF analysis to determine what types of precipitation patterns are pronounced over the Pacific. The results suggested that the first mode clearly represents the typical El Niño phenomenon, and the second mode associated with strong El Niño episodes explains the teleconnection pattern between the eastern equatorial Pacific (near Niño3 region) and the East China Sea, inferred from the eastward migration of the positive eigenvector. In this study, we utilize the same data set but focus our analysis on the associated eigenvalue time series and their correlation.

Fig. $3 \mathrm{~b}$ shows the time series of the principal components for precipitation. The first and second EOF modes account for 41.8 and $29.2 \%$ of the total variance, respectively. The amplitude of the first mode exhibits a very similar time evolution to that of the Niño index as shown in Fig. 1. The variation in time of the second mode increases noticeably at the strong peaks that occur during the 1982-1983 and 1997-1998 El Niño events. Therefore, we can define these 2 modes as 'typical (first) and strong (second) El Niño modes', respectively. A significant time lag also seems to exist between the typical and strong EOF modes.

(a) Eigenvector of the first and second mode for Precipitation
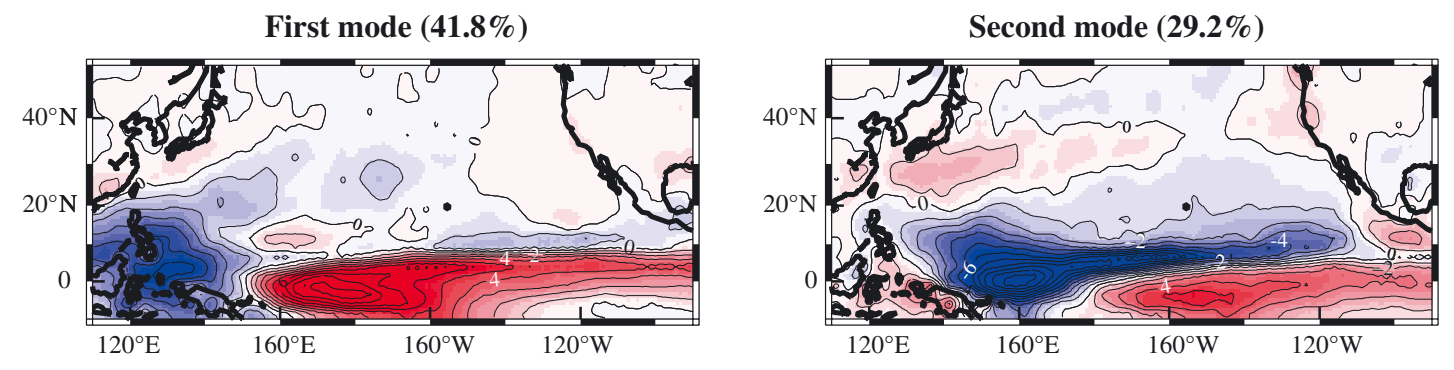

(b) Principal components (first (blue) and second (red) mode)
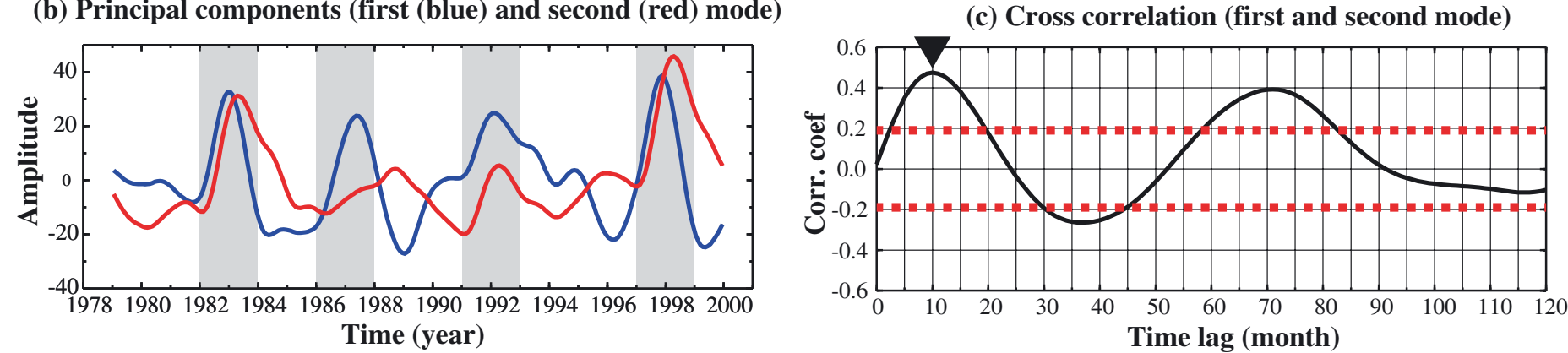

Fig. 3. (a) Spatial distributions of the first and second modes of the EOF analysis of precipitation data convoluted using a 24 mo Hanning filter. The units of eigenvectors are arbitrary. (b) Associated time series of first 2 modes; shaded regions indicate El Niño episodes. (c) Cross-correlation series between 2 modes with $99 \%$ confidence limits (dotted red lines). The inverted triangle marks the highest correlation point 
(a) Eigenvector of the first $(30.8 \%)$ and second $(19.9 \%)$ mode for SST
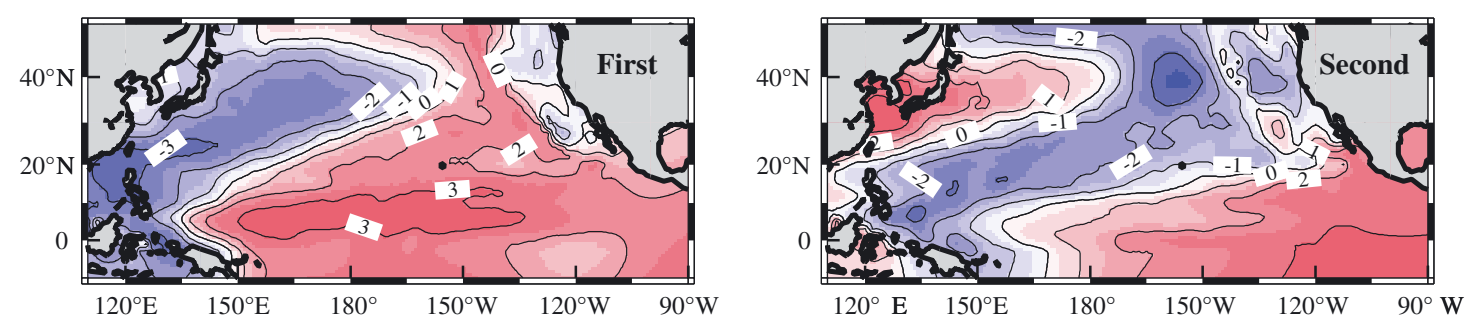

(b) Principal components (first (blue) and second (red) mode)

(c) Cross correlation (first and second mode)
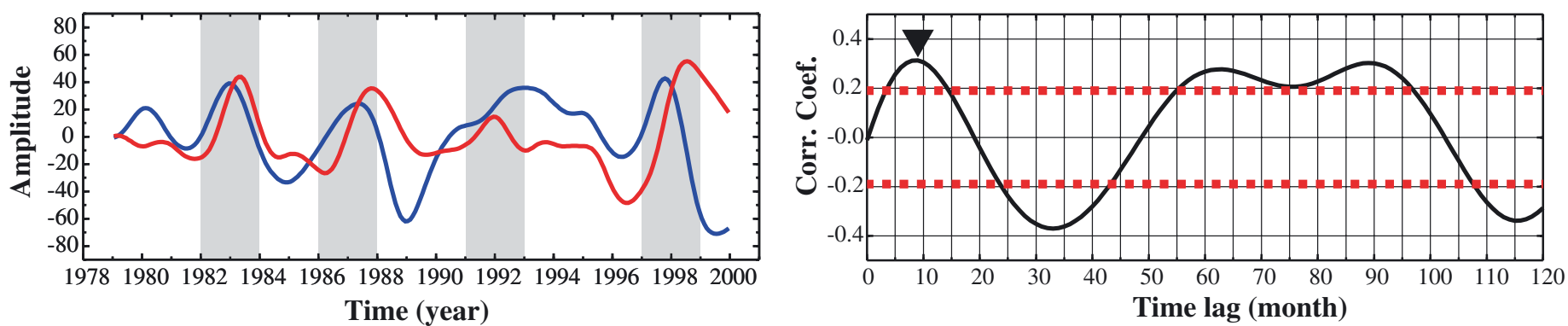

Fig. 4. (a) Spatial distributions of the first and second modes of the EOF analysis of NCEP sea-surface-temperature (SST) data convoluted using a 24 mo Hanning filter. The units of eigenvectors are arbitrary. (b) Associated time series of first 2 modes; shaded regions indicate El Niño episodes. (c) Cross correlation series between 2 modes with $99 \%$ confidence limits (dotted red lines). The inverted triangle marks the highest correlation point

(a) Eigenvector of the first (29.6\%) and second (17.3\%) mode for SSH
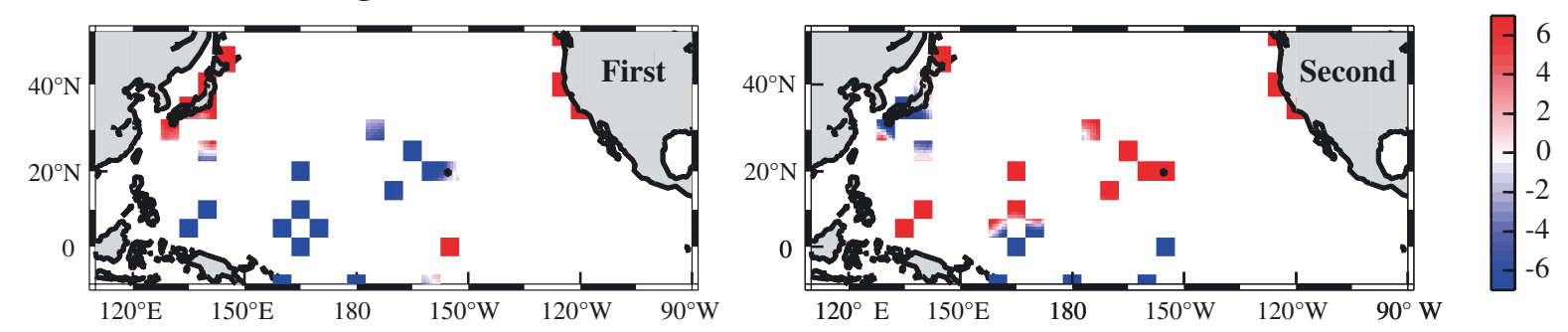

(b) Principal components (first (blue) and second (red) mode)
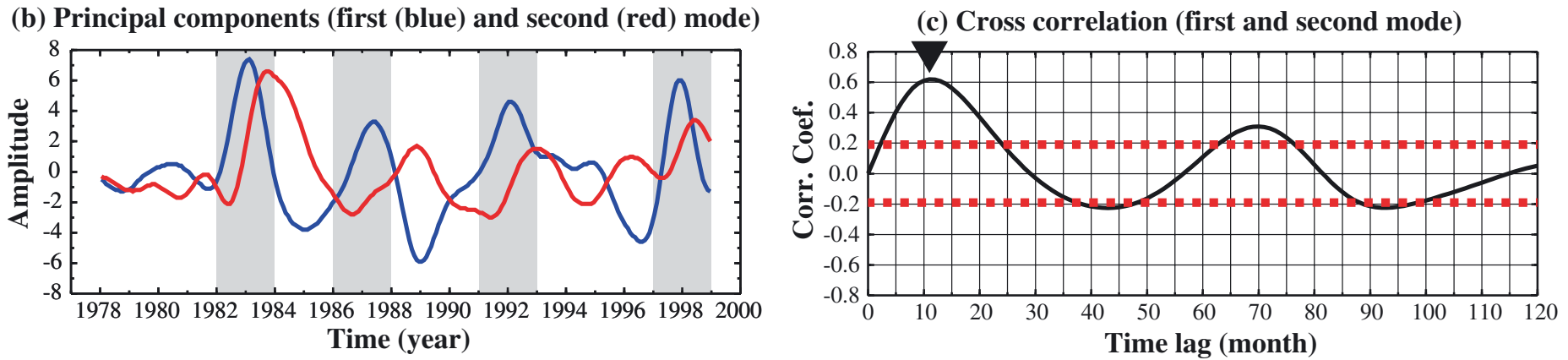

Fig. 5. (a) Spatial distributions of the first and second modes of the EOF analysis of UHSLC sea-surface-height (SSH) data convoluted using a 24 mo Hanning filter. The units of eigenvectors are arbitrary. (b) Associated time series of first 2 modes; shaded regions indicate El Niño episodes. (c) Cross correlation series between 2 modes with $99 \%$ confidence limits (dotted red lines).

The inverted triangle marks the highest correlation point 
The cross-correlation coefficient for each mode together with the $99 \%$ confidence intervals (equal to $\pm 3 / \sqrt{n}$, where $n=252$ ) is shown in Fig. 3c. The maximum value of the lagged correlation between the typical and strong modes is 0.47 with a time lag of 10 mo. This suggests that a strong El Niño signal positively affects both the East China Sea around the northwestern Pacific and the western coast of North America (see the spatial structure in Fig. 3a) after 10 mo when an El Niño occurred.

Fig. 4a shows the spatial-amplitude EOF functions of the filtered NCEP reanalysis SST data from 1979-1999. The first mode, representing $30.8 \%$ of the overall variance of SST anomaly in the Pacific Ocean, reveals the warm and cold areas, corresponding to the typical 'boomerang-shaped' correlation pattern over the western Pacific during El Niño periods suggested by Trenberth et al. (1998). A high SST anomaly over the East
China Sea in the northwest Pacific occurs when the second principal component (red line in Fig. 4b) is positive. The boomerang-shaped pattern moves further eastwards due to abnormally strong El Niño signals and interannual periodicity. The time difference of the associated time series between the first and second modes is about 9 mo at the 0.31 correlation coefficient (Fig. 4c). This suggests that SST in the northwest Pacific increases 9 mo after an El Niño occurs, which is well matched with that of the precipitation pattern in Fig. 3.

We also investigated $\mathrm{SSH}$ anomalies at the selected tidal-gauge stations in the Pacific area using the same analysis methods (Fig. 5). The most important fact is that spatial and temporal patterns of each mode (29.6 and $17.3 \%$ ) can be defined as typical and strong El Niño events, especially during 1982-1983. However, the SSH could not resolve the strong 1997-1998 El (a) 1st mode of PPT

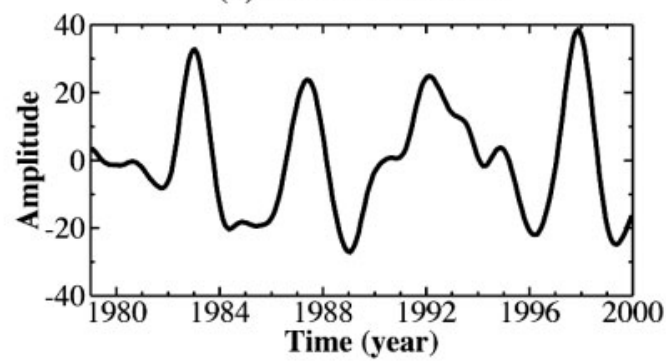

(c) Wavelet Power Spectrum

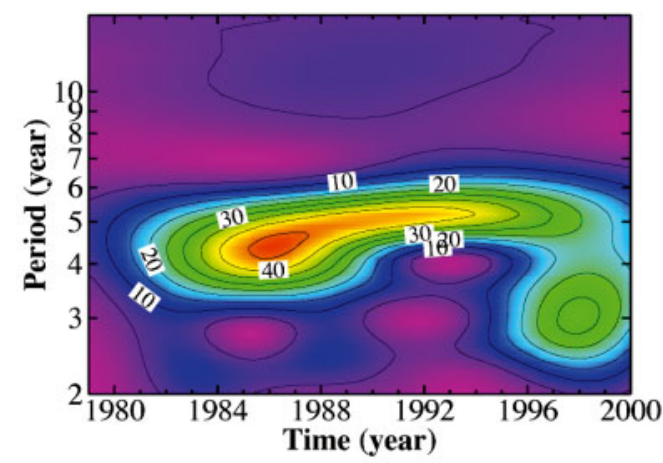

(e) Global Power Spectrum

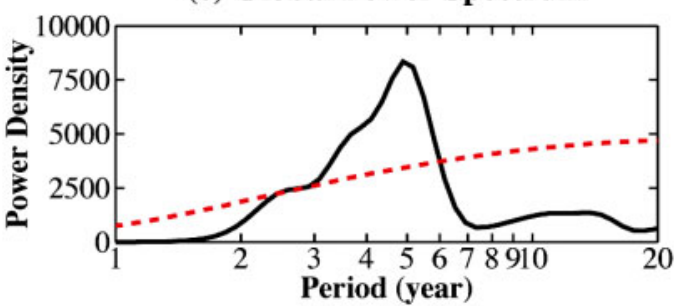

\section{(b) 2nd mode of PPT}

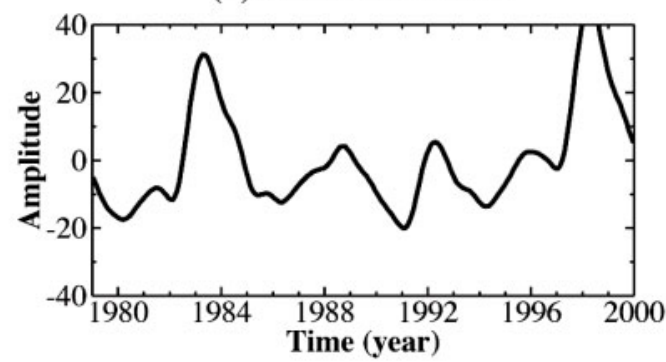

(d) Wavelet Power Spectrum

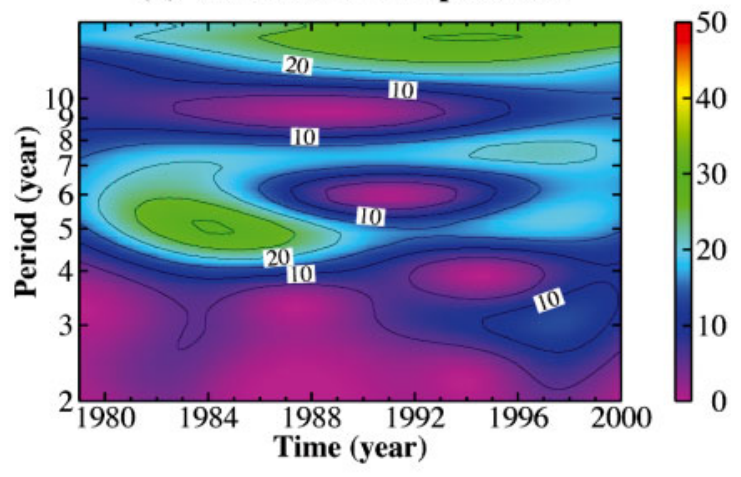

(f) Global Power Spectrum

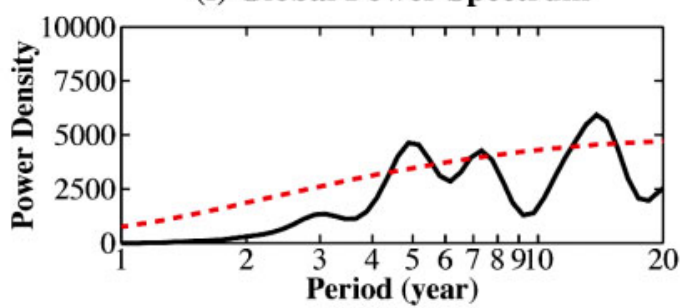

Fig. 6. (a,b) Time series of principal components of the (a) first and (b) second modes for precipitation. (c,d) Local wavelet power spectra of (c) first and (d) second modes of EOF. Colors represent different wavelet amplitudes, whose units are arbitrary. $(e, f)$ Global power spectra of (e) first and (f) second modes of EOF, together with $95 \%$ significance level 
(a) Nauru (blue), Christmas (green), Los Angeles (red)

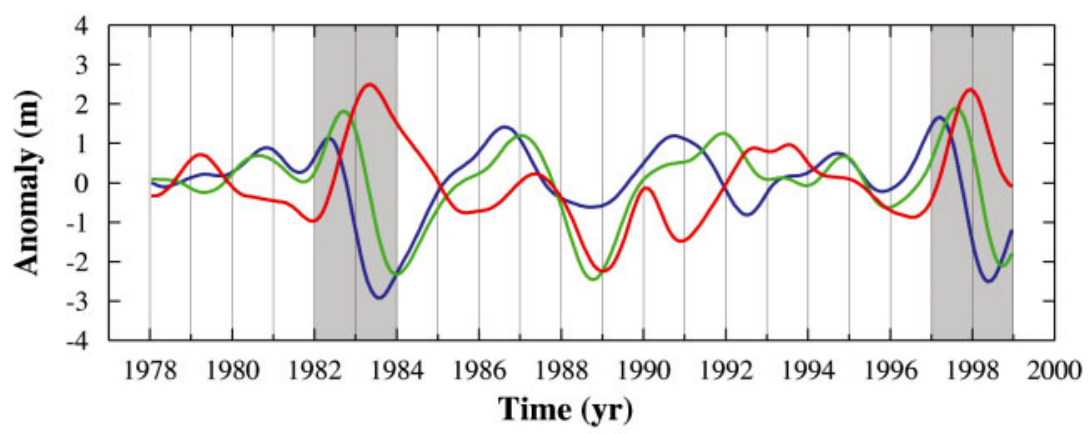

(b) Cross correlation between Nauru and Christmas

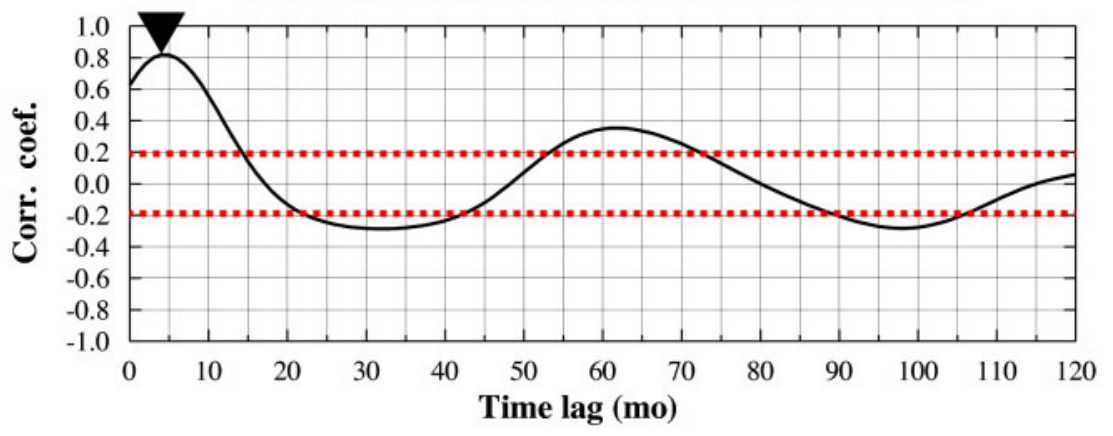

(c) Cross correlation between Christmas and Los Angeles

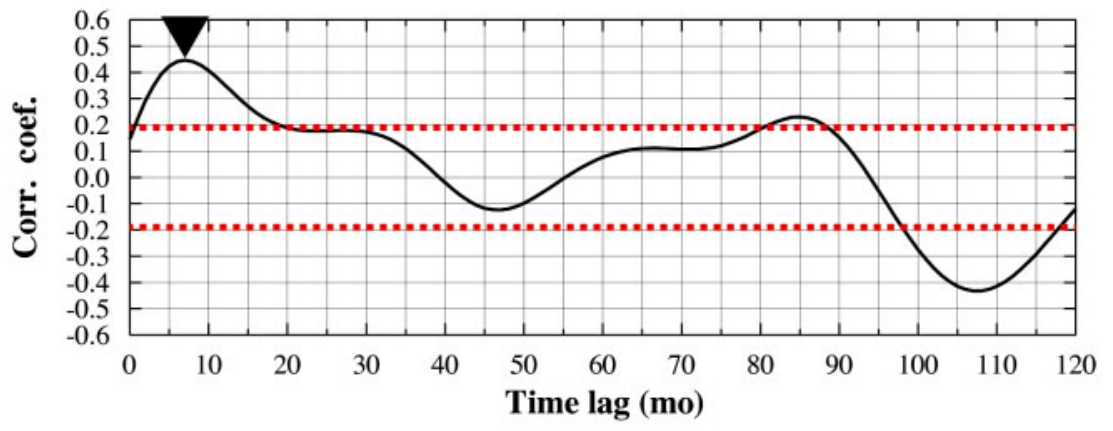

Fig. 7. (a) Time series of sea-surface height (SSH) at Nauru (blue), Christmas Island (green), and Los Angeles (red) convoluted using a 24 mo Hanning filter. Shaded regions correspond to strong El Niño periods. Cross-correlation series with a maximum delay of $10 \mathrm{yr}$ and $99 \%$ confidence limits $( \pm 3 / \sqrt{n}$, where $n=252)$ are calculated for the area (b) between Nauru and Christmas and (c) between Christmas and Los Angeles. The inverted triangles mark points of highest correlation the clear periodic characteristics of the interannual cycle; while the second mode represents an irregular, strong El Niño. It is useful to calculate power spectra of the individual time series to show the periodic characteristic between the 2 principal modes.

A significant interannual cycle of about 5 yr can be seen in Fig. 6a,c,e: the associated time series, wavelet power spectra, and total power spectra of the first mode of precipitation, respectively. In the wavelet transform, we find that a $5 \mathrm{yr}$ period is always dominant from the early 1980s to the late 1990s (Fig. 6c). Strong interannual variation over the whole time period shows the clear periodic characteristics of the interannual cycle of a typical El Niño.

As for the second mode, the total spectrum power density at a period of about 5 yr decreases, while that of longer decadal periods increases (Fig. 6f), compared to that of the first mode (Fig. 6e). There are 2 maxima in the wavelet spectra (Fig. 6d) on the interannual timescale: the $5 \mathrm{yr}$ period around mid-1984 and the $7 \mathrm{yr}$ around late 1998. These periods match well with the strong El Niño episodes (1982-1983 and 1997-1998), assuming a time lag of about 9 to $11 \mathrm{mo}$, which was confirmed by cross-correlation. From this, we conclude that the periodic characteristics of the second EOF mode is highly correlated with particularly strong El Niño events. The periodic characteristics of the first 2 EOF modes also exist in other variables such as SST and SSH, but are not shown here.
Niño in the second mode. Significant positive correlation is calculated at 11 mo lag period. The maximum correlation coefficient is 0.62 , which is much higher than that for other variables.

\section{PERIODICITY OF THE FIRST TWO MODES}

The previous section deals with the lag relationship between first 2 principal EOF modes. The first mode reflects the conditions of a typical El Niño, which has

\section{REGIONAL CORRELATION}

Sea-level data with a low-pass filter show an abnormal increase (or decrease) when 1982-1983 and 1997-1998 El Niños occurred (Fig. 7), with some time lags. The time series of sea levels at Nauru $\left(166.9^{\circ} \mathrm{E}\right.$, $\left.0.5^{\circ} \mathrm{S}\right)$ and Christmas Island $\left(157.5^{\circ} \mathrm{E}, 2^{\circ} \mathrm{N}\right)$ show that warm waters, once displaced in the warm pool region of the western Pacific, zonally propagate toward the eastern Pacific in the form of Kelvin waves. After hitting the West Coast of America, some of them move 
northwards to the off-equatorial regions, that is, passing by Los Angeles $\left(118.3^{\circ} \mathrm{W}, 33.7^{\circ} \mathrm{N}\right)$, in the form of coastal modified Kelvin waves. The westward propagation of the Rossby waves that are reflected back from the eastern boundary cannot be examined due to the lack of data in the eastern Pacific.

The maximum cross-correlation coefficients are $81.8 \%$ between Nauru and Christmas and 44.7\% between Nauru and Christmas, with time lags of 4 and 7 mo, respectively. Considering the time lag and the distance from Nauru, located in the warm pool region, to Los Angeles, on the western coast of America, it seems that a strong El Niño signal can be transferred at the speed of about $0.7 \mathrm{~m} \mathrm{~s}^{-1}(20000 \mathrm{~km}$ in $11 \mathrm{mo})$.

To examine the regional correlation with the Niño3 index $\left(150-90^{\circ} \mathrm{W}, 5^{\circ} \mathrm{N}-5^{\circ} \mathrm{S}\right)$ at the broad Pacific scale, a lagged correlation map contoured using the crosscorrelation coefficient, using $2^{\circ}$ by $2^{\circ} \mathrm{NCEP}$ reanalysis data, is shown in Fig. 8. In general, the spatial pattern shows a zonal seesaw structure between the equatorial western Pacific and the central (or eastern) Pacific. The zone where coefficients rapidly change shows the typical 'boomerang-shaped' pattern, as shown in Fig. 4a. Furthermore, its extension to the Timor Sea, which has similar negative correlation patterns with the Niño 3 region, explains the interannual variation of the IndoPacific throughflow (Murray \& Arief 1988, Hirst \& Godfrey 1993).

The maximum correlation coefficient shows an eastward propagation with an increase in the time lag. The delayed spatial pattern of about 6 to 9 mo is highly correlated with that of the strong El Niño EOF mode, as shown in Fig. 4a.

The period of interannual variation could be approximated to be about 3 to $4 \mathrm{yr}$, based on the fact that the correlation coefficient is reversed in about $21 \mathrm{mo}$.
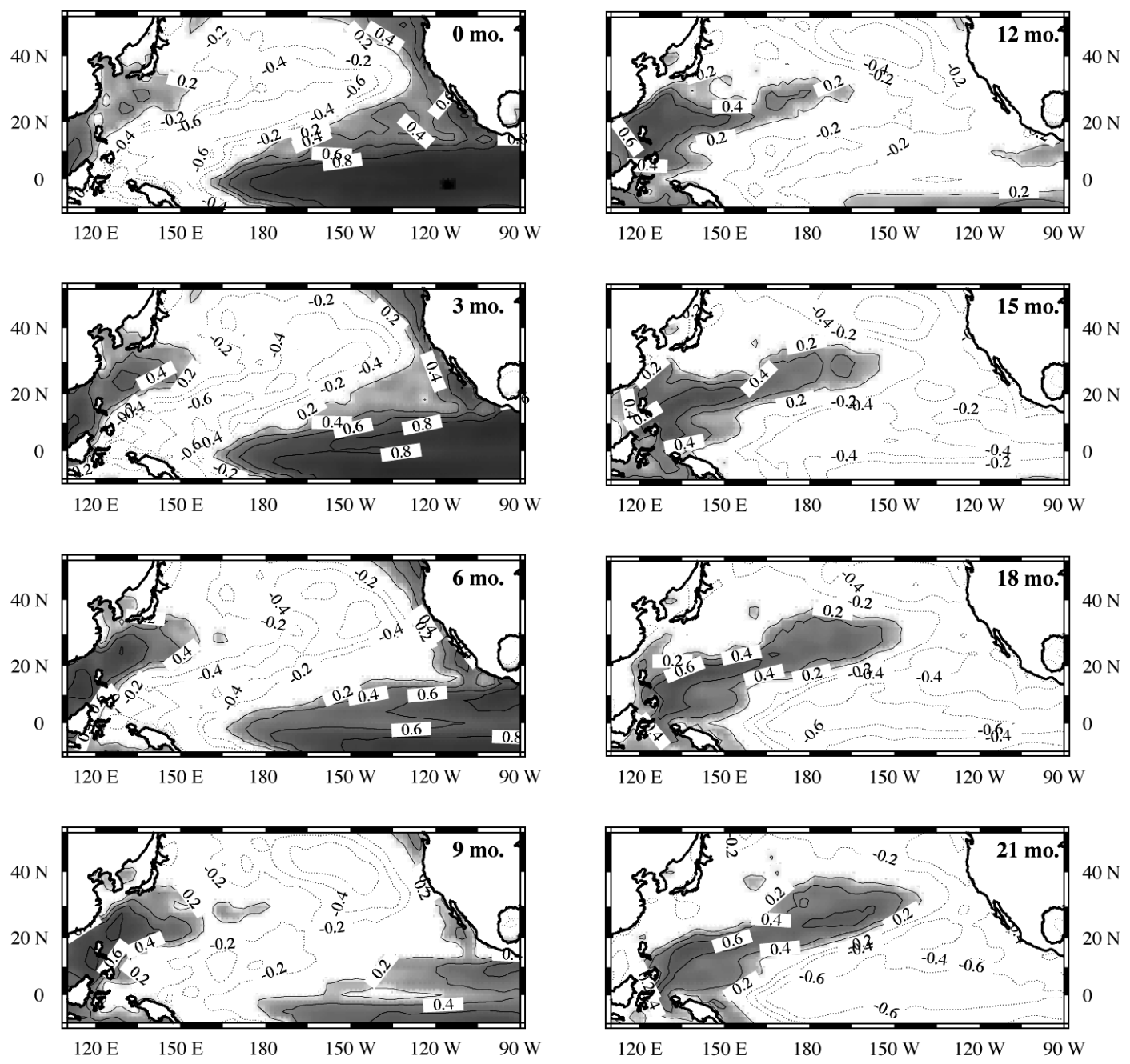

Fig. 8. Correlation map of the Niño3 $\left(150-90^{\circ} \mathrm{W}, 5^{\circ} \mathrm{N}-5^{\circ} \mathrm{S}\right)$ region. Contour interval of the cross-correlation coefficient is 0.2 . Shaded regions are the domains highly positively correlated $(\mathrm{r}>0.2)$ with the Niño3 region. Time lags of $0,3, \ldots, 21$ months are shown 


\section{SUMMARY AND DISCUSSION}

Periodicity, regional correlation and the spatial distribution of interannual variability of precipitation, SST, and SSH are analyzed from EOFs, spectral analysis using wavelet transform and a cross-correlation method. Most of the analyzed data have 2 significant modes that explain typical and strong El Niño signals. The 2 modes are highly correlated within a time delay of 9 to $11 \mathrm{mo}$. Spatial distributions of the strong El Niño mode from EOF analysis and the lagged correlation with Niño3 show a possible teleconnection pattern of the eastward migration of the Pacific climate system.

Interannual variability and its teleconnection have been actively studied over the last few decades. As this study suggests, understanding the transfer mechanism of El Niño signals and their correlations with midlatitudinal regions when strong El Niños occur may provide a significant basis for related studies. This study focused on the evolution of surface parameters only as an indicator of strong El Niños. Further studies will need to examine other non-surface variables such as upper-level atmospheric parameters or subsurface oceanic fields in order to understand the propagation process of strong El Niño signals.

Acknowledgements. The authors thank Dr Chris de Freitas, whose comments greatly improved the quality of the manuscript. We also thank the anonymous reviewers for their helpful comments and suggestions. This research was carried out as a part of 'A Study on the Monitoring of the Global Ocean Variability with ARGO Program' supported by Meteorological Research Institute/Korean Meteorological Administration.

\section{LITERATURE CITED}

Chang YS, An HS, Jeon D, Nam JC, Seo JW (2002) The El Niño signals contained in precipitation at the East China Sea. Clim Res 23:31-38

Davis RE (1976) Predictability of sea surface temperature and sea level pressure anomalies over the North Pacific Ocean. J Phys Oceanogr 6:249-266

Gael A, Thierry D (2002) Interannual sea level changes and associated mass transports in the tropical Pacific from TOPEX/Poseidon data and linear model results (1964-1999). J Geophys Res 107:1029-1067

Glantz M, Katz R, Nicolls N (1991) Telelconnections linking

Editorial responsibility: Chris de Freitas,

Auckland, New Zealand worldwide climate anomalies, Cambridge University Press, Cambridge

Hanawa KT, Watanabe N, Iwasaka T, Suga, Toba Y (1988) Surface thermal conditions in the western North Pacific. J Meteorol Soc Jpn 66:445-456

Hirst AC, Godfrey JS (1993) The role of the Indonesian throughflow in a global ocean GCM. J Phys Oceanogr 23:1057-1086

Horel JD, Wallace JM (1981) Planetary scale atmospheric phenomena associated with the Southern Oscillation. Mon Weather Rev 109:813-829

Jeon DC (1995) Sea level rise and coastal erosion in the Hawaiian Islands. PhD dissertation, University of Hawaii Honolulu

Jin FF, An SI, Timmermann A, Zhao J (2003) Strong El Niño events and nonlinear dynamical heating. Geophys Res Lett 30(3):1120, doi: 10.1029/2002GL016356

Meinen CS, McPhaden MJ (2001) Interannual variability in warm water volume transports in the equatorial Pacific during the 1998-99. J Phys Oceanogr 31:1324-1345

Meyers SD, Delly BG, O'Brien JJ (1993) An introduction to wavelet analysis in oceanography and meteorology: with application to the dispersion of Yanai waves. Mon Weather Rev 121:2858-2866

Miller L, Cheney R (1990) Large-scale meridional transport in the tropical Pacific Ocean during the 1986-1987 El Niño from Geosat. J Geophys Res 95:17905-17919

Murray SP, Arief D (1988) Throughflow into the Indian Ocean through the Lombok Strait, January 1985-January 1986. Nature 333:444-447

Rasmusson EM, Wallace JJ (1983) Meteorological aspects of the El Niño/Southern Oscillation. Science 222:1195-1202

Trenberth KE, Branstator GW, Karoly D, Kumar A, Lau NC, Ropelewski C (1998) Progress during TOGA in understanding and modeling global teleconnections associated with tropical sea surface temperatures. J Geophys Res 103:14291-14324

Weare BC, Navato AR, Newell RE (1976) Emperical orthogonal analysis of Pacific sea surface temperature. J Phys Oceanogr 6:671-678

White WB, Hasunuma K, Pazan SE, Li B (1985a) Dynamics of short-term climatic variability in the baroclinic structure of the western North Pacific. J Phys Oceanogr 15:386-402

White WB, Meyers G, Donguy JR, Pazan S (1985b) Short-term climatic variability in the thermal structure of the Pacific Ocean during 1979-1982. J Phy Oceanogr 15:917-935

Wyrtki K (1975) El-Niño: The dynamic response of the equatorial Pacific to atmospheric forcing. J Phy Oceanogr 5:572-584

Wyrtki K (1985) Water displacements in the Pacific and genesis of El-Niño cycles. J Geophys Res 90:7129-7132

Xie P, Arkin PA (1997) Global precipitation: a 17-year monthly analysis based on gauge observation, satellite estimates and numerical model outputs. Bull Am Meteorol Soc 78:2539-2558

Submitted: February 11, 2004; Accepted: May 25, 2004

Proofs received from author(s): June 25, 2004 